\title{
Multiphase Modeling of Droplet Fall using Euler-Euler Approach
}

\author{
P. Kwiatoń*, D. Cekus, M. Miara and I. Kubik-MaciąG \\ Czestochowa University of Technology, 42-201 Czestochowa, Poland \\ Doi: 10.12693/APhysPolA.138.276 \\ *e-mail: kwiaton@imipkm.pcz.pl
}

\begin{abstract}
This work pertains to dynamic's modeling of multiphase flows using two models of the Euler-Euler approach: VOF and Eulerian model. Different phases were treated as interpenetrating domains, and the theory of volume fraction was introduced. The mathematical model of multiphase flow consists of Navies-Stokes (NS) differential equations. The finite volume method was used for the numerical calculations. The droplet falling process was presented to show the differences in analyzed models. Numerical tests included flow analysis of the following phases: air, gasoil and water. Numerical results were presented as contours and time-function trend of volume fraction phases.
\end{abstract}

topics: droplet, multiphase flow, VOF model, Eulerian model

\section{Introduction}

Currently, in nature and industry, many types of flows are so-called mixture of phases. The physical approach to the phases of the state is gas, liquid or solid. However, in multiphase flow systems, this term is more widely used.

There are two main approaches to investigate multiphase flow systems in computational fluid dynamics (CFD) in the literature. These are EulerEuler approach and Euler-Lagrange approach [1-3], and both can be used inter alia for analysis of particle dynamics [1] or spray flow represented as droplet $[2,3]$. Due to the complexity of the phenomenon being analyzed, it is often necessary to combine the two approaches into one. In this case, the most commonly used method name is "mixed Euler-Euler/Euler-Lagrange" [4]. In this paper, the issue of multiphase flow modeling using different methods of the Euler-Euler approach was considered. The typical methods of this approach are: volume of fluid (VOF) [5], mixture model [6] and Eulerian model [7]. Work [5] presents a comparison of four distinct approaches of VOF method. The Coupled Level Set Volume of Fluid (CLSVOF) framework was used to conduct the evaluation. Article [6] pertains to $2 \mathrm{D}$ two-phase flow of gas-liquid model. The relative velocity and conservation equations for gas-liquid mixtures were taken into account. The Godunov finite volume methods were extended with the use of Slope Limiter Centered (SLIC) scheme. A new Eulerian model for compressible flow is presented in [7], where an inconsistency of Navier-Stokes equations is shown, taking into account the viscous and heat properties. Importantly, two models of the Euler-Euler approach is used to modeling a droplet flow.
In reference to the literature, droplet generation from the nozzle was studied in [8]. The two processes of droplet flow were analyzed: formation and falling. Numerical analysis was performed using commercial software ANSYS FLUENT that is used for mathematical modeling of various kinds of flow processes [9]. The implementation process and discretization of the domain are widely described, among others things, in [10-12]. The results are obtained based on the finite volume method (FVM).

\section{Model description}

Conservation laws of multiphase fluid flow include the following equations $[13,14]$ :

$$
\begin{aligned}
& \frac{\mathrm{d} q}{\mathrm{~d} t}=-q\left(\nabla \cdot \boldsymbol{u}_{1}\right), \\
& \frac{\mathrm{d}(1-q)}{\mathrm{d} t}=-(1-q)\left(\nabla \cdot \boldsymbol{u}_{2}\right),
\end{aligned}
$$

where $q$ denotes the volume fraction of the sharp/dispersed phase taking values from 0 to 1 .

The mathematical model of the droplet multiphase flow falling in horizontal tube presented here is based on the solution of the following differential equations [13-17]:

- mass conservation:

$$
\frac{\partial}{\partial t} \rho_{q}+\nabla \cdot\left(\rho_{q} \boldsymbol{u}_{q}\right)=0
$$

- momentum conservation:

$$
\begin{gathered}
\frac{\partial}{\partial t}\left(\rho_{q} \boldsymbol{u}_{q}\right)+\nabla \cdot\left(\rho_{q} \boldsymbol{u}_{q} \boldsymbol{u}_{q}\right)= \\
\quad-\nabla p_{q}+\nabla \cdot \boldsymbol{\tau}_{q}+\boldsymbol{F}_{q},
\end{gathered}
$$

- energy conservation:

$$
\begin{aligned}
& \frac{\partial}{\partial t}\left(\rho_{q} E_{q}\right)+\nabla \cdot\left(\rho_{q} \boldsymbol{u}_{q} E_{q}\right)=-\nabla \cdot\left(\boldsymbol{u}_{q} p_{q}\right) \\
& \quad+\nabla \cdot\left(\boldsymbol{u}_{q} \cdot \boldsymbol{\tau}_{q}\right)+\boldsymbol{u}_{q} \cdot \boldsymbol{F}_{q}-\nabla \cdot \boldsymbol{J}_{i q}+J_{E q},
\end{aligned}
$$


where $\rho$ is a density of sharp/dispersed phase $q$, $\boldsymbol{u}_{q}$ is a velocity of flow, $p_{q}$ is a pressure, $\tau_{q}$ is a deviatoric stress tensor, $E_{q}$ is a total energy per unit, $\boldsymbol{F}_{q}$ is an external force tensor, $\boldsymbol{J}_{i q}$ is a heat flux in $q$-phase and $J_{E q}$ is a heat source.

The equations listed above (3)-(5) are the basis for modeling multiphase flows for both turbulent and laminar flows $[14,15]$. In the Euler-Euler approach presented in this paper, different phases can be treated as interpenetrating mediums. This approach introduces the concept of the volume phase fraction, which depending on the adopted model and can be represented in various forms. In the volume of fluid model, the interface between the analyzed phases is also being tracked. This is achievable [18, 19] by solving

$$
\frac{\partial q}{\partial t}+\nabla \cdot(q \boldsymbol{u})=0 .
$$

In the Eulerian model, the volume fraction equation takes the form $[18,19]$ :

$$
V_{i}=\int_{V} q_{i} \mathrm{~d} V,
$$

For both (6) and (7), the algebraic sum of phase volume fraction is presented in the form:

$$
\sum_{i=1}^{n} q_{i}=1 .
$$

\section{Results and discussion}

This work pertains to the comparison of two models of Euler-Euler approach for multiphase flow phenomenon. Droplet formation and falling were investigated with the use of VOF and Eulerian model. The studied problem concerned 2D, transient and pressure-based solver with gravity acting. The geometry (Fig. 1) used in this work can be divided into two domains: the nozzle filled with a secondary phase and a tube filled with air.

The material properties of the considered phases are presented in Table I. The analyzed computational domain was divided into 52,124 finite elements. User-defined function (UDF), which was formulated based on examples available in the ANSYS Support Center [20], was used for the droplet formation process. In this procedure, the inlet velocity condition increased rapidly to values $4.21 \mathrm{~m} / \mathrm{s}$ and then decreases to zero after $10 \mu \mathrm{s}$. The simulation tests were run for $100 \mu \mathrm{s}$. The simulation model

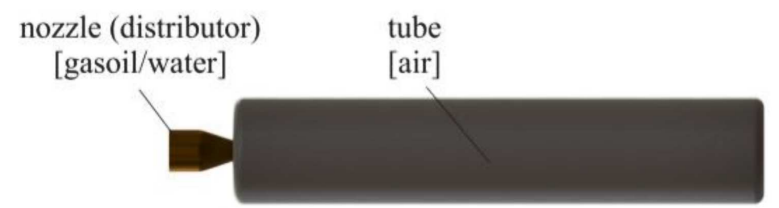

Fig. 1. Geometry and initial phase distribution in the analyzed cases.
Mechanical parameters of the phases.

TABLE I

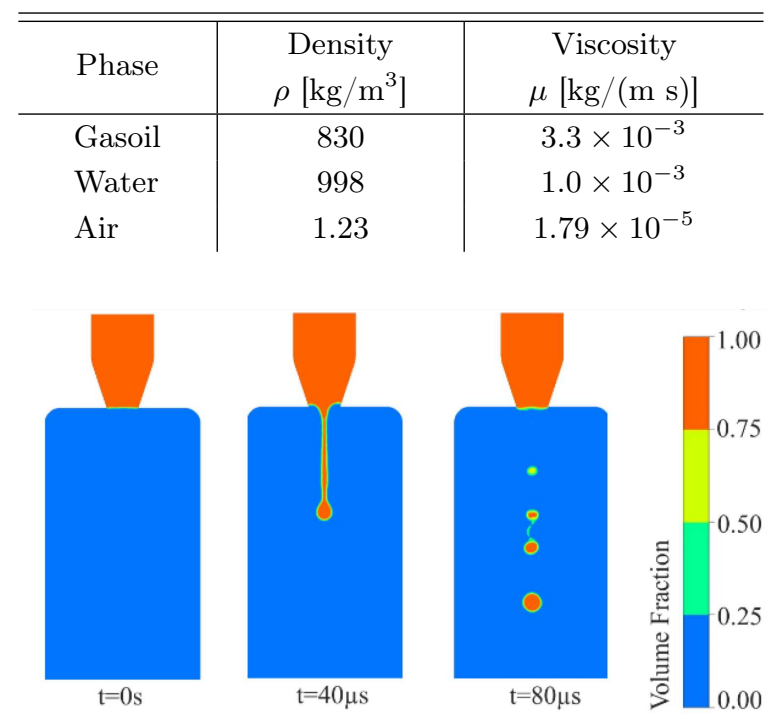

Fig. 2. Droplet formation for: VoF model, waterair phases.

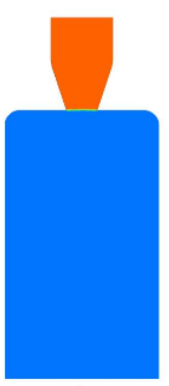

$\mathrm{t}=0 \mathrm{~s}$
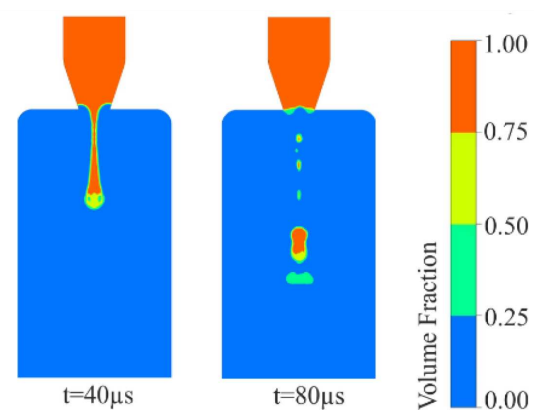

Fig. 3. Droplet formation for: Eulerian model, water-air phases.

took into account the surface tensions of the analyzed fluids, which was $0.073 \mathrm{~N} / \mathrm{m}$ for water-air case and $0.036 \mathrm{~N} / \mathrm{m}$ for gasoil-air example.

Numerical simulations were carried out for four cases differing in the applied multiphase model and the type of secondary phase (Figs. 2-4). The effect of density and viscosity on the size and time formation of the droplet was analyzed.

Comparing Euler models, it was noticed that in the Eulerian model (Fig. 3) the droplet has more irregular edges than in the VOF model (Fig. 2). It was also observed that droplets in the Eulerian model generated more slowly.

In subsequent stages, the water phase was replaced with a higher viscosity fluid - gasoil. In both cases, only one drop was found in this case (Fig. 4 and 5). Droplet formation time is similar to the previously analyzed water-air phase (Fig. 2 and 3 ). In this case, however, the dispersed phase was much larger. Time function trend of volume fraction phases at a point located in the axis of symmetry was presented in Fig. 6. It was noted that in the fourth case (Fig. 6b), in which the gasoil-air 

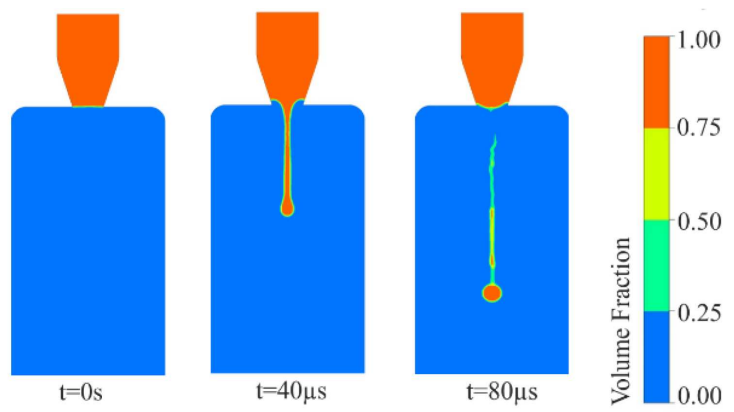

Fig. 4. Droplet formation for: VOF model, gasoilair phases.
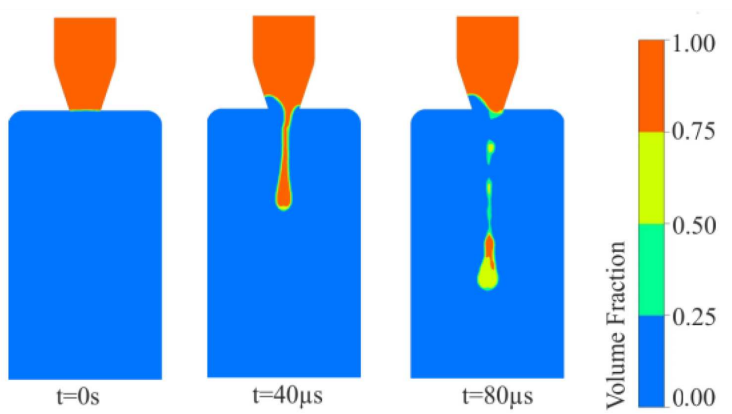

Fig. 5. Droplet formation for: Eulerian model, gasoil-air phases.
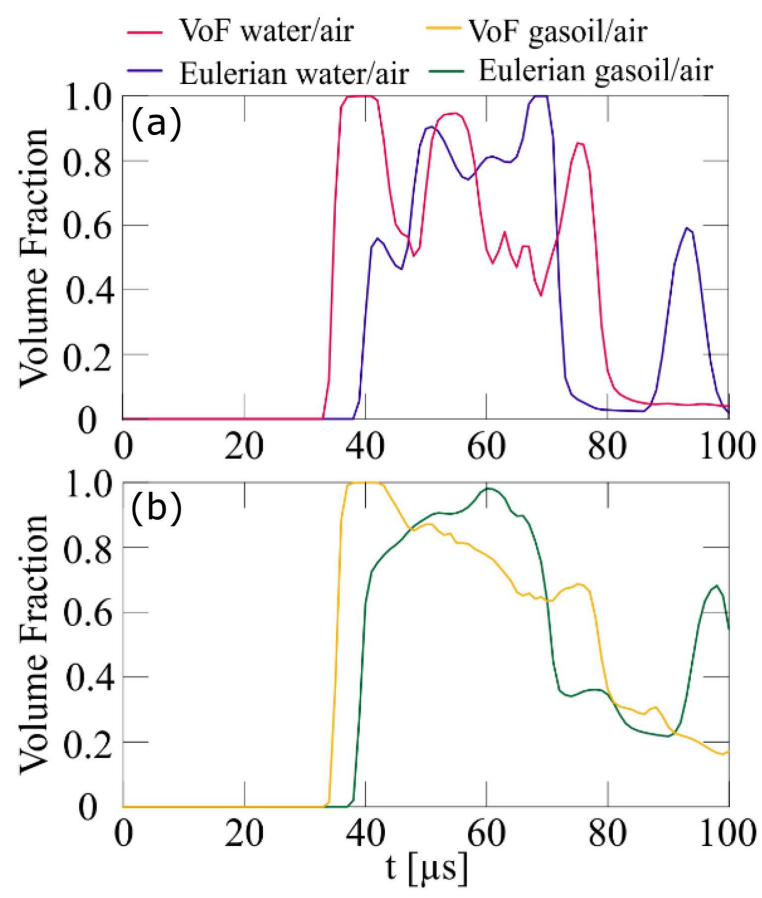

Fig. 6. Time function trend of volume fraction for (a) water/air (b) gasoil/air phases.

phase flow was analyzed for the Eulerian model, the volume fraction did not reach the value of 1 . This means that the generated droplet was a mixture of two phases - the total secondary phase was not achieved.

\section{Conclusions}

Modeling of multiphase flows using two models of the Euler-Euler approach: VOF and Eulerian model was presented in this work. The mathematical model consists of mass, momentum and energy conservation. The finite volume method was used for the numerical calculations. The numerical simulation involved a flow analysis of the following phases: water-air and gasoil-air. Numerical results were presented as contours (Figs. 2-5) and timefunction trend (Fig. 6) of volume fraction phases. Based on the obtained results, it can be concluded that the VOF model is a more appropriate choice for the analysis of droplet flow. The analysis also showed that for liquids with a higher viscosity value, droplet formation is extended over time. The numerical simulations should be verified through experimental tests.

\section{References}

[1] W. Adamczyk, A. Klimanek, R. Białecki, G. Węcel, P. Kozołub, T. Czakiert, Particuology 15, 129 (2013).

[2] S. Subramaniam, Prog. Energy Combust. Sci. 39, 215 (2012).

[3] M. Sanjose, J.M. Senoner, F. Jaegle, B. Cuenot, S. Moreau, T. Poinsot, Int. J. Multiphase Flow 37, 514 (2011).

[4] G.V. Messa, G. Ferrarese, S. Malavasi, Wear 342-343, 138 (2015).

[5] W. Aniszewski, T. Menard, M. Marek, Comput. Fluids 97, 52 (2014).

[6] D. Zeidan, P. Bahr, P. Farber, J. Grabel, P. Ueberholz, Comput. Fluids 181, 90 (2018).

[7] M. Svard, Physica A 506, 350 (2018).

[8] S. Liu, S. Shen, X. Mu, Y. Guo, D. Yuan, Int. J. Multiphase Flow 118, 10 (2019).

[9] R. Gnatowska, T. Rybak, AIP Conf. Proc. 1648, 850125 (2015).

[10] T.S. Zaripov, O. Rybdylova, S.S. Sashin, Int. Commun. Heat Mass Transfer 97, 85 (2018).

[11] M. Sosnowski, J. Krzywański, R. Scurek, Entropy 21 (11), 1047 (2019).

[12] M. Sosnowski, R. Gnatowska, J. Sobczyk, W. Wodziak, J. Theor. Appl. Mech. 57, 833 (2017).

[13] F. Chen, H. Hagen, in: OASIcs (OpenAccess Series in Informatics), Eds. A. Middel, I. Scheler, H. Hagen, Schloss DagstuhlLeibniz-Zentrum fuer Informatik, Dagstuhl 2011, 11-19.

[14] C. Drumm, S. Tiwari, J. Kuhnert, H.J. Bart, Comput. Chem. Eng. 32, 2946 (2008). 
[15] K. Hiltunen, A. Jasberg, S. Kallio, H. Karema, M. Kataja, A. Koponen, M. Manninen, V. Taivassalo, Multiphase Flow Dynamics: Theory and Numerics, VTT Technical Research Centre of Finland, Espoo 2009.

[16] Z. Saternus, W. Piekarska, M. Kubiak, T. Domański, L. Sowa, Procedia Eng. 136. 95 (2016).
[17] L. Sowa, T. Skrzypczak, P. Kwiaton, Arch. Foundry Eng. 19(4), 91 (2019).

[18] J.U. Brackbill, D.B. Kothe, C. Zemach, J. Comput. Phys. 100, 335 (1992).

[19] D.K. Walters, N.M. Wolgemuth, Int. J. Numer. Methods Fluids 60, 893 (2018).

[20] ANSYS, ANSYS Support Center. 